\title{
Conselho de saúde como espaço emblemático para o trabalho acadêmico em comunidades
}

Health council as an emblematic space for academic work in communities

El consejo de salud como espacio emblemático para el trabajo académico en las comunidades

Luís Felipe Ferro - Universidade Federal do Paraná | Curitiba | Paraná | Brasil | E-mail: luisfelipeferro@gmail.com | Orcid: https://orcid.org/0000-0001-8935-104X.

Resumo: Os Conselhos de Saúde configuram possibilidades para a participação popular na elaboração, fiscalização e execução das políticas públicas de Saúde. Contudo, diferentes problemáticas são evidenciadas cotidianamente para tal exercício. Paralelamente, críticas vêm apontando tanto o distanciamento das universidades das demandas comunitárias, quanto sua postura predatória, muitas vezes explorando unicamente dados para pesquisas ensimesmadas, sem retribuição para as comunidades. Este artigo pretende promover reflexões sobre potencialidades da parceria entre Universidades e Conselhos de Saúde. Desta forma, ressalta-se a contribuição dos Conselhos para promover diagnósticos mais apurados da saúde e da participação popular; parcerias comunitárias para a elaboração, desenvolvimento, validação e captação de recursos para o desenvolvimento de ações acadêmicas e construção permanente de conhecimento.

Palavras-chave: Saúde coletiva. Participação comunitária. Política pública.

\begin{abstract}
The Health Councils constitute a possibility for popular participation in the development, supervision and execution of public health policies. However, several problems are evident every day for this exercise. In parallel, criticisms accuse several Universities of both its distance from community demands and its predatory stance, exploiting data for research without concrete compensation for the communities. In this context, this article aims to contribute to the weaving of reflections on the potential of the partnership between University and Health Councils. Thus, it's highlighted the contribution of the Councils to promote: more accurate diagnoses of health and popular participation; community partnerships for the elaboration, development, validation and fundraising of academic actions; permanent construction of knowledge.
\end{abstract}

Keywords: Colletive health. Community participation. Public Policy.

Resumen: Los Consejos de Salud constituyen una posibilidad para la participación popular en el desarrollo, supervisión y ejecución de políticas públicas de Salud. Sin embargo, varios problemas se evidencian todos los días para este ejercicio. En paralelo, críticas han sido hechas contra ciertas direcciones de las acciones de la Universidad y acusan tanto su distancia de las demandas comunitarias, como su postura depredadora, explotando datos para investigaciones sin retribución concreta para las comunidades. El ensayo crítico que se presenta, pretende contribuir a la tejeduría de reflexiones sobre el potencial de la asociación entre la Universidad y los Consejos de Salud para guiar y validar las acciones de enseñanza, investigación y extensión, las aliando intrínsecamente a las demandas comunitarias de Salud.

Palabras clave: Salud pública. Participación de la comunidad. Política pública.

- Recebido em: 18 março 2020 - Aprovado em: 31 março 2020 e-ISSN: 2177-5788

DOI: https://doi.org/10.22484/2177-5788.2020v46n1p107-126

Copyright @ 2020. Conteúdo de acesso aberto, distribuído sob os termos da Licença Internacional da Creative Commons-CC BY-NC-SA - Atribuição Não Comercial Permite distribuição e reprodução, desde que atribuam os devidos créditos à publicação, ao autor(es) e que licenciem as novas criações sob termos idênticos. 


\section{Introdução}

Atualmente, diferentes enunciadores como Kawasaki (1997), Freire (1999), Schmidt (2006) e Sobral (2000), vêm apontando de maneira crítica o distanciamento de algumas Universidades e/ou de seu corpo técnico das problemáticas da comunidade em que se insere. Alguns autores, como Ferreira e Oliveira (2009), Santos (1999), Santos e Almeida Filho (2008), ressaltando a potência dessas instituições para a elaboração e desenvolvimento de estratégias colaborativas voltadas a propor respostas às demandas comunitárias, ainda sublinham a importância da validação democrática destas ações por diferentes membros da comunidade.

Tais reflexões vêm amadurecendo propostas organizacionais que, paulatinamente, procuram enfrentar a distância entre a Universidade e as problemáticas sociais. Neste sentido, Programas governamentais de incentivo a práticas integradas entre Universidade e comunidade, tais como - Programa de Educação pelo Trabalho para a Saúde (PET-Saúde), o Programa de Extensão Universitária (ProExt), dentre outros, assim como propostas de construção de conhecimento pautadas em metodologias ativas, como as de Mitre et al. (2008) e Berbel (2011), vem apresentando tanto base financeira/estrutural, como didático-pedagógica para enfrentar este quadro.

Fruto de ensaio pautado na experiência de 10 anos advinda da participação do docente como conselheiro do Conselho Municipal de Saúde de Curitiba e de membro e coordenador de sua Comissão de Saúde Mental, assim como delegado e observador de diferentes Conferências de Saúde, o presente material pretende promover reflexões e descrever algumas possibilidades estratégicas de articulação de ações de ensino/pesquisa/extensão com as comunidades, tendo, como base estrutural, os espaços de controle social - foco dado aos Conselhos de Saúde. 


\title{
2 Controle social e os conselhos de saúde: conceitos e estrutura
}

A partir de diferentes movimentos sociais que tomaram corpo a partir da década de 1970 no contexto brasileiro, segundo Cortes (2002), pautados no enfrentamento da ditadura, conquistas diversas foram reposicionando a relação Estado/Sociedade e proporcionando estrutura legislativa para a participação da sociedade no controle e elaboração das ações públicas. Desta forma, a Constituição Federal de 1988, a lei 8.080 de 1990 (BRASIL, 1990a) e a lei 8.142 de 1990 (BRASIL, 1990b) se tornaram marcos jurídicos para a previsão e regulamentação desta participação no campo da saúde e foram delineando o que vem sendo conhecido como controle social.

\begin{abstract}
No Brasil, a expressão controle social tem sido utilizada como sinônimo de controle da sociedade civil sobre as ações do Estado, especificamente no campo das políticas sociais, desde o período da redemocratização dos anos de 1980. A utilização da expressão com este sentido foi propiciada pela conjuntura de lutas políticas pela democratização do país frente ao Estado autoritário, implantado a partir da ditadura militar (BRAVO; CORREIA, 2012, p. 127).
\end{abstract}

O Controle Social se instaura, neste contexto, com a intenção de prover estrutura para a fiscalização e elaboração conjunta das ações públicas por diferentes segmentos sociais. Enquanto proposta de organização do Sistema Único de Saúde, conforme Brasil (1990b), prevê a criação de Conferências e Conselhos de Saúde.

As Conferências de Saúde são previstas com a periodicidade máxima de 4 anos e intencionam possibilitar o levantamento de diferentes demandas da população nos âmbitos nos quais se realiza, sejam municipais, estaduais, federal e, em alguns municípios, locais e distritais. As Conferências de Saúde, desta forma, conforme Ministério da Saúde (2002), instauram espaços institucionais para a discussão e elaboração de diretrizes pelos diferentes segmentos da comunidade (usuários do SUS, prestadores de serviço, trabalhadores e gestores) e edificam, como produto final, um relatório que reúne as propostas discutidas, com o intento de prover guias para as ações públicas. 
Ao Conselho de Saúde, por sua vez, é reservado o caráter permanente e deliberativo. A atuação deste equipamento se debruça, conforme consta em Brasil (1990b), na elaboração de estratégias e no controle da execução da política de saúde correlata e envolvendo aspectos econômicos e financeiros. Tanto Conselhos de Saúde, como Conferências, possuem composição paritária de representantes dos usuários da saúde em relação ao conjunto dos demais segmentos, quais sejam: $25 \%$ gestores e prestadores de serviço; $25 \%$ profissionais da saúde.

Enquanto estrutura organizacional para procurar ampliar o alcance e eficiência de suas ações, alguns Conselhos de Saúde se subdividem em Comissões Temáticas. As comissões, logo, possibilitam suporte às decisões e ações dos Conselhos de Saúde em sua área de especialidade. O Conselho Municipal de Curitiba, a título de exemplo, possui as seguintes comissões temáticas: Comissão de Assistência à Saúde; Comissão de Saúde da Pessoa Idosa; Comissão de Saúde da Mulher; Comissão de Saúde da Criança e do Adolescente; Comissão de Saúde do Homem; Comissão de Saúde da Pessoa com Deficiência; Comissão de Saúde Bucal; Comissão de Vigilância em Saúde; Comissão de Vigilância em Saúde DST/Aids; Comissão de Vigilância em Saúde Ambiental; Comissão Intersetorial de Saúde do Trabalhador; Comissão de Saúde Mental; Comissão de Orçamento e Finanças; Comissão Intersetorial de Recursos Humanos; Comissão de Urgência, Emergência e Assistência Hospitalar; Comissão Permanente de Revisão de Regimento, Regulamento e Legislação do Conselho Municipal.

Ainda, em alguns municípios, pode ser evidenciada a existência de Conselhos em Distritos de Saúde e mesmo em alguns equipamentos, como Unidades Básicas e Centros de Atenção Psicossocial (CAPS), denominados, respectivamente, de Conselhos Distritais e Locais de Saúde.

Em ambos, Conselhos e Conferências de Saúde, segundo Assis e Villa (2003), é almejado que o processo de negociação entre os diferentes segmentos sociais possa tomar lugar e culmine na composição de guia para 
as ações públicas. Vale frisar, ainda, conforme Silva, Cruz e Melo (2007) e Bastos, Santos e Tovo (2009), o importante papel dessas instâncias democráticas para garantir o acesso da população a informações sobre as ações públicas, incluídas as dados econômico-financeiros e possibilidade de análise, avaliação e do acompanhamento.

\section{Conselhos de saúde e pesquisas com comunidades: parcerias para o enfrentamento de problemáticas comunitárias e para a construção de conhecimento}

Embora os conselhos de saúde, para Cortes (2009), venham apresentando diversas barreiras e limitações para o exercício do controle social, tal configuração apresenta-se emblemática ao que se intenciona aqui aprofundar - sua proficiência enquanto espaço ímpar para proporcionar articulação de ações de ensino/pesquisa/extensão, base triangular da Universidade, de maneira a responder a diferentes demandas comunitárias.

A composição paritária do conselho, seja local, distrital, municipal, estadual ou federal, possibilita a congregação no mesmo espaço de diferentes segmentos da comunidade. Desta forma, gestores, prestadores de serviço, trabalhadores e usuários do SUS se unem para discutir temas e ações de relevância para enfrentar problemáticas da Saúde em sua esfera de atuação e tal encontro pode proporcionar potencialidades ímpares para o trabalho acadêmico.

Em passo inicial, ao se envolver com o controle social, o pesquisador/docente irá se deparar fenomenicamente com representantes dos diferentes segmentos, todos apresentando um denominador comum: sua vinculação com o território e suas problemáticas. Este panorama possibilita grande contribuição para a elaboração do diagnóstico situacional da saúde na esfera de atuação do conselho e, adicionalmente, para a estruturação de parceiras que fortaleçam de atividades de ensino, pesquisa e extensão. Para além, os participantes dos espaços de controle social podem prover guias que venham a ampliar a potência de tais ações, indicando indivíduos/instituições-chave para sua condução mais profícua. 
Um pesquisador que, por exemplo, debruce-se a descrever as limitações do Serviço de Atendimento Móvel de Urgência (SAMU) para o atendimento em saúde mental sob a perspectiva dos usuários, em um determinado município, pode encontrar suporte a partir de um representante de uma associação de usuários presente no espaço do conselho de saúde. A Associação pode ter acesso a diferentes usuários que vêm acionando o SAMU com frequência e/ou possuir listagem de indivíduos que chegam até ela com reclamações estruturadas sobre o equipamento. $O$ representante pode, ainda, dado sua proximidade ao tema, auxiliar o pesquisador a elaborar caminhos pragmáticos para atingir seus objetivos da pesquisa.

É importante ressaltar, também, a pluralidade dos agentes presentes nos espaços de controle social e sua potencialidade estratégica para estruturação de ações acadêmicas ${ }^{1}$. Tais agentes, gestores, usuários, trabalhadores ou prestadores de serviços, podem proporcionar diferentes aproximações metodológicas de determinado objeto de estudo e, concomitantemente, amplo campo reflexivo e estratégico para o desenho de caminhos metodológicos. Ao pesquisador/docente caberá a organização estratégica destas diversas contribuições para o endosso das ações acadêmicas. Tal empreitada pode contribuir para dirimir dificuldades presentes no percurso vivenciado pelo docente para a edificação de ações acadêmicas.

Um ponto imprescindível para a maturidade do pesquisador/docente em sua imersão nos espaços de controle social, contudo, conforme o CNS (2003), é a necessária clareza sobre a presença de relações de poder singulares e de interesses diversificados e, muitas vezes, divergentes. $\mathrm{Na}$ experiência com o Conselho Municipal de Saúde de Curitiba foi relevante tomar atenção para incluir e colocar sob análise os possíveis percalços e

\footnotetext{
1 A partir deste momento, utilizar-se-á ações acadêmicas para descrever as diferentes ações de ensino, pesquisa e/ou extensão.
} 
conflitos de diferentes ordens que possam advir deste processo. A exploração das dificuldades do SAMU para a atenção em Saúde Mental, em continuidade do exemplo acima citado, pode não ser de interesse da gestão do município, a qual pode até mesmo criar obstáculos para a realização da pesquisa. Um projeto de extensão elaborado para fortalecer, ainda a título de exemplo, determinados segmentos de usuários para a reivindicação de seus direitos e/ou para a exposição pública de sua agressão pode ser, igualmente, mal quisto por outro segmento.

Operar e fortalecer ações acadêmicas nos espaços de controle social, desta forma, exige o vislumbre nítido das diferentes forças e relações de poder presentes. Neste sentido, caberá ao docente, a partir de tal apropriação, configurar parcerias, manejando forças dissidentes, que promovam as ações acadêmicas e o enfrentamento das problemáticas comunitárias que Ihe são foco.

Representantes de diferentes entidades vinculadas ao Conselho de Saúde podem, ainda, procurar parcerias para a realização de ações formativas e/ou de pesquisas e/ou de extensão voltadas ao enfrentamento de problemáticas vivenciadas na esfera de atuação do conselho, delineando possíveis rumos às ações acadêmicas. Diferentes conselheiros que compõem esta arena política ainda podem se posicionar unidos à gestão para o encaminhamento de recursos, tanto humanos como financeiros, para a composição destas ações, fazendo com que, desta maneira, a aplicação do orçamento público seja direcionada para responder de maneira concreta às demandas comunitárias, fortalecendo, desta forma, as ações acadêmicas.

Situações problemáticas vivenciadas no âmbito do conselho, como a falta de formação dos profissionais da saúde sobre determinados temas, podem ser gatilho para a composição, por exemplo, de cursos de extensão. A proposta de tais cursos, assim, relacionar-se-ão de maneira intrínseca com as demandas comunitárias, em contraposição à não rara inexatidão da oferta de determinados cursos, ligados muitas vezes a interesses 
particulares de alguns docentes. Ainda, tais ações podem contar com o aporte de recursos e contrapartidas das instituições presentes no conselho, sejam vinculadas à gestão, aos trabalhadores ou aos usuários.

Cabe lembrar outra faceta importante da participação nos espaços de controle social: a constante atualização de informações. Neste sentido, novas portarias e legislações; programas, projetos e ações realizadas pelo poder público e seus resultados, não restritos ao âmbito de atuação do conselho; atualizações quanto à participação de agentes em eventos técnico-científicos; resultados de reuniões entre gestores e as pactuações realizadas, podem ser apresentados constantemente nos conselhos de saúde. O Conselho de Saúde, ainda, é permeado pelo conhecimento de diferentes agentes a ele vinculados, logo, usuários, familiares, profissionais da saúde, prestadores de serviço e gestores, compõem rico panorama de conhecimentos diversificados, contributivos, sem dúvida, para a ampliação do espectro situacional visível do docente. Desta forma, o conselho, para além de um espaço estratégico para a composição de ações acadêmicas e parcerias, afirma sua contribuição como locus para formação permanente do docente, o qual, inserindo-se neste espaço, também pode contribuir para a construção compartilhada de conhecimento com aos demais agentes.

\section{Conselhos de saúde: entre a imersão no controle social, a função de docente e o papel de militante}

Ao docente que se insere, pelas variadas mudanças profissionais, dentro de um novo território de trabalho ou mesmo para o docente que desenvolve sua ação profissional em uma localidade há um determinado espaço de tempo, os Conselhos possibilitam a apreensão de diferentes facetas da realidade até então desconhecidas por conta de sua composição plural, já exposta anteriormente. Contudo, para promover a composição compartilhada e parceira das ações acadêmicas com os Conselhos de Saúde, algumas diretrizes podem ser importantes. 
Ressaltada a importância estratégica dos conselhos de saúde para o conhecimento de toda uma rede comunitária de atores e instituições e para o diagnóstico das problemáticas e das potências do território, cabe sublinhar também as diferentes e orgânicas possibilidades de trajetória operacional próprias a este processo. Neste sentido, a inclinação e interesses acadêmicos do docente podem servir de guia para tal imersão, aproximando-o de determinado campo e não de outro.

Para compor este trabalho de maneira pragmática, afirmando cotidianamente a potência da Universidade para o enfrentamento conjunto de problemas coletivos, de maneira articulada com as forças presentes nos Conselhos de Saúde, cabe inicialmente definir a esfera ou equipamento de saúde que representam com maior relevância o interesse do docente. Neste sentido, cabe ao docente, de acordo com seus interesses, escolher o conselho que mais potencializa seu objeto/objetivos acadêmicos, seja o Conselho de determinada Unidade de Saúde ou o de esfera distrital, municipal, estadual ou mesmo federal.

A aproximação inicial do conselho, local, distrital, municipal, estadual ou federal, requer, contudo, operacionalização: a posse de informações sobre datas e horários de realização das reuniões do Conselho de Saúde se faz, logo, necessária. A forma de envolvimento com o conselho também pode ser configurada, logo inicialmente, a partir da figura de conselheiro de saúde, representante de determinada instituição.

Diferentes conselhos, ainda, possibilitam a participação de diferentes membros da comunidade na qualidade de observador/ouvinte, tendo qualquer cidadão direito à voz, mas não ao voto decisório das pautas do conselho. O vínculo inicial do docente como observador/ouvinte pode proporcionar, também, maior proximidade quanto ao funcionamento e normativas do conselho em questão, assim como constituição de relação com as entidades que lhe são pertencentes.

Aos Conselhos de Saúde, como espaço de controle social, compete a tarefa de construir, acompanhar e fiscalizar as ações públicas do campo da 
saúde em seu âmbito de ação. Logo, as deliberações e assuntos abordados pelo conselho podem ter espectro bastante ampliado, abrangendo o controle de zoonoses, vigilância sanitária, saúde mental, saúde do idoso, da mulher etc. Ora, se tal amplitude, por um lado, é interessante para o conhecimento das problemáticas, programas, projetos e ações variados desenvolvidos pela Saúde de um município, por exemplo, pode desestimular, por outro, a participação no controle social, caso o foco de interesse for reservado à determinada área de atuação.

Conforme acima exposto, para poder viabilizar o trabalho, diferentes conselhos de saúde se subdividem em comissões temáticas. Logo, caso o brilho dos olhos ou a inclinação pessoal ou profissional do docente penderem, por exemplo, para a área da saúde mental, a vinculação ao conselho por meio desta comissão pode prover maior foco e, com isso, responder de maneira mais exata às necessidades que o conduziram a esta arena democrática. Muitas vezes a oficialização da vinculação ao conselho em suas comissões temáticas é ainda facilitada.

A transposição da qualidade de observador/ouvinte para conselheiro ou comissionado também pode ser interessante para ampliar as possibilidades de atuação no conselho. Vivenciamos, em nossa experiência, um movimento da gestão e da secretaria do conselho para restringir algumas ações, como visitas e avaliações de equipamentos de saúde, a indivíduos com vinculação oficial ao conselho e/ou comissão. A oficialidade pode se tornar, desta maneira, um importante benefício para a imersão no controle social.

A oficialização da participação como conselheiro de saúde, contudo, é bastante singular de conselho para conselho. Em alguns Conselhos de Saúde a eleição dos conselheiros se dá na oportunidade das conferências de saúde. A partir do envolvimento no Conselho elegido, os passos para formalizar a participação por esta via poderão ser vislumbrados com maior detalhamento. Na experiência junto ao Conselho Municipal de Saúde de Curitiba, uma clareza foi importante: embora o docente possa ter formação 
como profissional da saúde, é também funcionário da educação, e pode optar estrategicamente por uma ou outra qualidade - profissional da saúde, da educação ou mesmo como usuário do SUS - para conseguir a representação. Um termômetro interessante na experiência junto ao Conselho Municipal de Saúde de Curitiba, para guiar tal opção, foi o envolvimento com instituições com direcionamentos e interesses similares ao do docente.

A imersão nos espaços de Controle Social, possivelmente de maneira invariável, tem a potência de apresentar personagens empenhados na construção concreta dos ideais do SUS, gestores, prestadores, profissionais ou representantes de usuários. Com o risco de destoar da forma argumentativa até então apresentada, valho-me, neste momento, de alguns apontamentos delineados pela filósofa alemã Hannah Arendt e pelo geógrafo Milton Santos.

Em sua obra A Condição Humana, de 2004, de Hannah Arendt retoma a história da Grécia Antiga, berço da democracia. Arendt (2004) ressalta ao leitor a importância impelida por aquela comunidade quanto à ação política, um dos pontos de diferenciação entre homens e animais. A ação política, aqui, consistia na possibilidade de o homem influir nos caminhos a serem percorridos por sua comunidade - qualidade intrínseca ao Ser Humano, segundo a autora. Em contexto brasileiro contemporâneo, a partir do capitalismo que aqui se desenvolve, esta qualidade - já considerada a mais nobre reservada ao Ser Humano - é cada vez mais alijada da população. Assim, a participação política e o poder decisório nas ações públicas ficam muitas vezes restritos a determinados segmentos e aos seus interesses.

Milton Santos, em sua análise do conceito de território, apresenta esta friç̧ão de interesses contrapondo o espaço local ao global.

Há um conflito que se agrava entre um espaço local, espaço vivido por todos os vizinhos, e um espaço global, habitado por um processo racionalizador e um conteúdo ideológico de origem distante e que chegam a cada lugar com os objetos e as normas estabelecidos para servi-los [...] Na democracia de mercado, o território é o suporte de 
redes que transportam regras e normas utilitárias, parciais, parcializadas, egoístas (do ponto de vista dos atores hegemônicos), as verticalidades, enquanto as horizontalidades hoje enfraquecidas são obrigadas, com suas forças limitadas, a levar em conta a totalidade dos atores. A arena da oposição entre o mercado -que singularizae a sociedade civil -que generaliza- é o território, em suas diversas dimensões e escalas (SANTOS, 2005, p. 259).

Ao risco, apresentado a todo instante, da dominação globalizante, o autor reforça a importância da análise pormenorizada do território, em sua constituição histórica, no encalço de lugares de resistência possíveis. Valhome de outra citação do autor:

\begin{abstract}
Por enquanto, o lugar -não importa sua dimensão- é a sede dessa resistência da sociedade civil, mas nada impede que aprendamos as formas de estender essa resistência às escalas mais altas. Para isso, é indispensável insistir na necessidade de conhecimento sistemático da realidade, mediante o tratamento analítico desse seu aspecto fundamental que é o território (o território usado, o uso do território). Antes, é essencial rever a realidade de dentro, isto é, interrogar a sua própria constituição neste momento histórico (SANTOS, 2005, p. 259-60).
\end{abstract}

A participação constante nos espaços de Controle Social cada vez mais proporcionará a vivência deste equipamento como um lugar de resistência. Em contraste à lustrosa e romântica concepção que possa rodear tal afirmação, sublinha-se que os conselhos de saúde apresentam dificuldades constantes. A assunção dos espaços de Controle Social enquanto lugares de resistência não deve tomar lugar sem receio ou infindáveis alertas. O lugar é espaço físico de resistência, de constrangimentos, de luta e de exposições constantes, permeado por diferentes interesses e composto por suas manobras e estratégias - lugar onde a dominação globalizante, como proposta por Milton Santos, apresenta-se de maneira consistente e, por vezes, escusa.

Ainda que diferentes limitações se apresentem cotidianamente, os Conselhos de Saúde podem, neste contexto, proporcionar palco estrutural para disputas diversas, configurando-se como um dos possíveis lugares de resistência da sociedade brasileira contemporânea. Uma pergunta, neste 
momento, é inevitável: O Conselho de Saúde propiciaria que sorte de resistência? De quem e para quem?

Talvez aqui uma postura mais madura para elaborar tais questões seja não tomar como verdadeira a assunção do Conselho como caminho inequívoco para defesa dos amplos interesses da sociedade. Destaca-se aqui o adjetivo inequívoco como uma forma de reafirmar: a complexidade das relações de poder presentes nesta arena de disputas; a incipiência das ações de vários Conselhos, muitas vezes restritos a encaminhamentos burocráticos; e mesmo a proficiência de determinados segmentos em terem aprovadas, de maneira escamoteada, várias de suas demandas, mesmo que visivelmente contrárias aos interesses de grande parte da população. Os amplos interesses, por sua vez, tomam realce crítico neste quadro, de vastidão de demandas sociais e de complexa disputa política. Acredita-se, contudo, que os Conselhos de Saúde proporcionam espaço, já configurados legislativamente e edificados a partir de importantes conquistas políticas, de participação e, talvez, de emancipação - espaços que podem proporcionar a iluminação de determinados processos deliberativos, muitas vezes escusos, inserindo atores sociais diversos nesta arena política de disputa.

Dando andamento ao corpo propositivo que se pretende delinear em maior profundidade neste item, a experiência vivenciada de progressiva imersão no Conselho Municipal de Saúde de Curitiba proporcionou, sem dúvidas, uma maior aproximação com o território, suas dificuldades e agentes sociais atuantes, assim como uma maior potência para a composição parceira de ações de enfrentamento às problemáticas comunitárias. Ainda, tal envolvimento, profissional, relacional, pessoal, afetuoso e cidadão, foi, inevitável e paulatinamente, desenvolvendo um papel de militância na área.

Se, por um lado, o desenvolvimento da condição de cidadão, advindo do exercício da ação política, conforme proposta por Hannah Arendt (2004), pode tomar lugar nos espaços de Controle Social, por outro, o papel de 
docente não pode ser esquecido. A diferenciação de tais papéis é a do caminho sobre o fio da navalha.

Enquanto docente, é possível destinar parte da estrutura da Universidade para enfrentar determinadas problemáticas e/ou compor pesquisas ou ações extensionistas sobre temas emergentes nos Conselhos de Saúde e/ou suas Comissões. Contudo, se a pesquisa acerca das percepções de usuários do atendimento do SAMU na Saúde Mental, exemplo acima citado, é realizada, ela deve ser conduzida pelo pesquisador, reafirmando continuamente seu papel ético e compromisso com o conhecimento - procurando, no fio da navalha, anular o papel de militante. A pergunta da pesquisa deve, inquestionavelmente, ser respondida com o máximo de ética e sem contaminação de qualquer posicionamento político - até mesmo seu desenho metodológico deve ser mais apurado para procurar dar contorno a este ponto.

Uma pesquisa partida de demandas de um Conselho Municipal de Saúde, exemplo ainda mais emblemático, pode guiar um docente das Ciências Contábeis a realizar uma pesquisa sobre o orçamento destinado a ONGs contratadas pela Secretaria Municipal de Saúde. Seu trabalho pode comprometer diferentes sujeitos participantes dos espaços de controle social que, em outras oportunidades, puderam se apresentar como parceiros para várias ações acadêmicas.

Explicita-se aqui um impasse vivenciado. A cidade de Curitiba é uma capital com contingente populacional sem igual no Estado. Tal panorama confere ao município a possibilidade de implementar pontos de atenção da Saúde Mental que municípios menores não possuem - para o trabalho enquanto pesquisador da saúde isto proporcionaria a instauração de campo de pesquisa de contribuição ímpar. Contudo, tomar tal direção pode comprometer de maneira severa o exercício cidadão e militante, por exemplo, no controle das ações públicas e impor ao docente amarras para apresentar abertamente denúncias sobre as ações públicas. Como instaurar, por exemplo, um estágio em um dos CAPS do município e, ao 
saber em momentos de supervisão das dificuldades do local, se restringir ao silêncio? Como expor de maneira aberta as mazelas de um parceiro? Como gerenciar o conflito interno militante $X$ pesquisador?

Neste sentido, cabe ressaltar, embora com a brevidade aqui necessária, a potência da pluralidade das articulações possíveis, assim como as diferentes amarras e possibilidades próprias às diferentes instituições e lideranças locorregionais presentes nos espaços dos Conselhos de Saúde, para, estrategicamente, promover a visibilidade de determinadas problemáticas comunitárias.

\title{
5 Conselhos de saúde e comunidades interpretativas: a validação das ações acadêmicas em questão
}

\begin{abstract}
Numa sociedade cuja quantidade e qualidade de vida assentam em configurações cada vez mais complexas de saberes, a legitimidade da universidade só será cumprida quando as atividades, hoje ditas de extensão, se aprofundarem tanto que desapareçam enquanto tais e passem a ser parte integrante das atividades de investigação e ensino (SANTOS, 1999, p. 53).
\end{abstract}

Em crítica à figura do pesquisador como agente social incumbido do estudo solitário e munido de um suposto poder para desvelar os mais diversos fenômenos sociais, Schmidt (2006) advoga pelo conceito de comunidades interpretativas.

A autora defende a necessidade de que as pesquisas participantes sejam compartilhadas e reconhecidas pela comunidade a que se destinam, as quais interpretariam determinados resultados e possibilitariam a elaboração de sentido mútuo, por vezes contrastantes, por vezes compartilhados, mas que, de forma ou outra, comporia contribuição marcante para fortalecer a pesquisa em sua concisão argumentativa e validade científica.

Caso o colega das Ciências Contábeis, por exemplo, percebesse alguns dados conflituosos com as contas públicas, possivelmente a gestão (em especial das ONGs expostas) iria analisar os dados em pormenores para encontrar possíveis gafes metodológicas do pesquisador. 
Observatórios Sociais e outras instituições integrantes dos Conselhos de Saúde poderiam também imergir nos dados e amadurecê-los ainda mais. A pesquisa com o SAMU poderia chegar à sua coordenação, que se posicionaria frente aos dados, adensando sua análise e, com isso, sua contribuição social. Ainda neste caso, uma ONG de proteção da pessoa com transtorno mental, por exemplo, poderia refutar a forma de coleta de dados e direcionar o pesquisador para a composição de ferramenta mais sensível ao objeto estudado. O Conselho de Saúde e/ou Comissão a ele vinculada poderia ter contribuição ímpar, desta maneira, na validação dos dados da pesquisa e/ou seu amadurecimento.

A validação das ações acadêmicas, contudo, não se restringem à pesquisa. Programas e Projetos de extensão; cursos e eventos diversos; qualidade do perfil de egressos e da estrutura curricular; ações de ensino vinculadas à graduação e/ou pós-graduação, ao exemplo de metodologias ativas; enfim, todo o escopo de ações acadêmicas poderia receber contribuições construtivas desta comunidade interpretativa.

\begin{abstract}
À Universidade compete organizar esse compromisso, congregando os cidadãos e universitários em autênticas comunidades interpretativas que superem as usuais interações, em que os cidadãos são sempre focados a renunciar à interpretação da realidade social que Ihes diz respeito (SANTOS, 1999, p. 52).
\end{abstract}

Neste panorama, Universidade se uniria indissociavelmente à sua comunidade, em uma relação longitudinal e parceira com diferentes agentes sociais para seu enfrentamento de problemáticas coletivas, superando a relação predatória da coleta de dados e consecutivo distanciamento, muitas vezes evidenciada na prática acadêmica, ou mesmo o seu distanciamento ensimesmado, acertadamente apontado por Chauí (2001). Assim, os Conselhos de Saúde, foco deste manuscrito, afirmariam sua potência como uma das possíveis comunidades interpretativas, configurando estrutura propícia para tais encontros coletivos e possibilitando guias para a validação de ações acadêmicas diversas. 
O valor formativo e libertário do conhecimento cresce na medida da democratização de sua construção, divulgação e apropriação, ou seja, na medida em que é concebido por e para coletivos dos quais participam uns e outros na perspectiva de alcançar um bem comum. (SCHMIDT, 2006, p. 39).

A divulgação da produção técnico-científica da Universidade talvez pudesse ser, ainda neste registro, ampliada. Artigos e trabalhos em eventos científicos, muitas vezes destinados e/ou com circulação restrita somente a determinados grupos profissionais, poderiam encontrar expansão em sua relação orgânica com a comunidade e, com isso, maior efetividade em sua proposta transformadora.

\section{Educação e saúde: parceria estratégica}

Quanto ao possível receio a respeito da circunscrição da autonomia do docente nas ações acadêmicas que lhe dizem respeito, cabe afirmar que os Conselhos de Saúde enquanto espaços estratégicos para prover guias ao trabalho acadêmico não são de qualquer forma impositivos. Ao docente, em sua margem de manobra, caberia pensar e estruturar as mais variadas ações de ensino/pesquisa/extensão dentro de sua área de enfoque, a partir das problemáticas vivenciadas e elaboradas pelo Conselho. Tal processo, contra qualquer assunção de uma possível diminuição da autonomia do docente e/ou de sua instituição, ratifica, sobremaneira, a subjetividade do profissional e a posição estratégica de sua instituição enquanto parceiros sociais para o enfrentamento de problemáticas comunitárias.

A errônea suposição a respeito de uma possível serialização e/ou despersonalização das ações acadêmicas e/ou de sua submissão a interesses de determinados segmentos sociais tombaria, afirmando constantemente a potência da contribuição coletiva na construção comunitária, própria aos sujeitos envolvidos nos conselhos em tela, agora comunidades interpretativas, em sua configuração histórica, temporal e singular - ressaltando, talvez, a nobreza da ação política referida pela filósofa Arendt (2004). Para tanto, ressalta-se a importância do exercício social, cotidiano e permanente, de estruturar instituições e parcerias REU, Sorocaba, SP, v. 46, n. 1, p. $107-126$, jun. 2020 
comunitárias diversas, que garantam estabilidade de seus profissionais e a não captura de suas potencialidades por determinados segmentos socialmente mais fortalecidos, no sentido de garantir a consolidação gradual da democracia.

Embora se tenha priorizado neste manuscrito a análise sobre as potencialidades e desafios para a consolidação de ações parceiras entre Universidade e Conselhos de Saúde, acredita-se que as reflexões apresentadas podem ser expandidas, guardadas as devidas limitações, para a participação docente junto a Conselhos diversos, sejam da Educação, Assistência Social, Fóruns etc.

Ainda, cabe situar que as reflexões aqui presentes não dizem respeito exclusivamente aos docentes vinculados exclusivamente ao campo da Saúde. O Conselho de Saúde pode (e assim é desejado) ser habitado por docentes de diversas áreas, Ciências Contábeis, Direito, Educação etc., assim como a frequência de docentes vinculados à área da saúde podem ser contributivas junto aos Conselhos de Assistência Social, Educação etc.

Como vimos, contudo, embora a participação popular no Controle Social esteja prevista legislativamente na Saúde desde 1990, os Conselhos de alguns equipamentos de saúde, de distritos, de municípios, de estados ou mesmo da federação têm participação bastante incipiente ou mesmo nula de alguns grupos populacionais, caso que, por si só, pode proporcionar, de imediato, a elaboração de ações diversas pelo docente, envolvendo toda a potência de sua instituição e de parcerias comunitárias, para o fortalecimento da participação popular nestes espaços.

Nesse sentido, cabe ressaltar que este ensaio, pautado na experiência do autor no fortalecimento da interface entre controle social e ações acadêmicas, teve como base estrutural um Conselho de Saúde com participação plural, contando, por um lado, com representantes de determinadas instituições e grupos populacionais bastante ativos e, por outro, com a ausência ou fragilidade intensa de representantes de outros grupos populacionais. Logo, distante de propor aqui generalizações a serem 
aplicadas em todas as realidades brasileiras, as quais comportam conselhos com maior ou menor participação popular, acredita-se, sim, que a vinculação com espaços de controle social diversos podem expor tanto o diagnóstico da situação da saúde, como o da participação popular, de maneira que estes se tornem propulsores para a elaboração de ações diversas que fortaleçam tanto a saúde como a mobilização popular e, com ela, a democracia, tendo, como um dos potentes comburentes para esta reação, uma Universidade engajada e comprometida socialmente.

Apregoa-se ao SUS, enquanto parte integrante de seu campo de atuação, a ordenação da formação de recursos humanos na área de Saúde. Talvez possa ser a partir do estabelecimento dos Conselhos de Saúde como uma das instâncias democráticas-guia para as ações acadêmicas que tal prerrogativa possa se tornar cada vez mais pragmática, convocando a Universidade a destinar variados esforços de maneira a responder de modo operacional às demandas sociais, tornando-se, acima de tudo, uma potente parceira comunitária.

\section{Referências}

ARENDT, Hannah. A condição humana. 10. ed. Rio de Janeiro: Forense Universitária, 2004.

ASSIS, Marluce M. A.; VILLA, Tereza C. S. O controle social e a democratização da informação: um processo em construção. Rev. Latino-am Enfermagem, São Paulo, v. 1, n. 3, p. 376-82, 2003.

BASTOS, Francisco A.; SANTOS, Everton; TOVO, Maximiano F. Capital social e Sistema Único de Saúde (SUS) no Brasil. Saúde Soc., São Paulo, v. 18, n. 2, p. 177-188, 2009.

BERBEL, Neusi A. N. As metodologias ativas e a promoção da autonomia de estudantes. Semina: Ciências Sociais e Humanas, Londrina, v. 32, n. 1, p. 2540, 2011.

BRASIL. Lei no 8.080, de 19 de setembro de 1990. Dispõe sobre as condições para a promoção, proteção e recuperação da saúde, a organização e o funcionamento dos serviços correspondentes e dá outras providências. Diário Oficial da União, 19 set. 1990a.

BRASIL. Lei No 8.142, de 31 de dezembro de 1990. Dispõe sobre a participação da comunidade na gestão do Sistema Único de Saúde (SUS) e sobre as transferências intergovernamentais de recursos financeiros na área da saúde e dá outras providências. Diário Oficial da União, 31 dez. 1990b. 
BRAVO, Maria Inês I. S.; CORREIA, Maria Valéria C. Desafios do controle social na atualidade. Serv. Soc. Soc., São Paulo, v. 109, p. 126-50, 2012.

CHAUÍ, Marilena S. Escritos sobre a universidade. São Paulo: UNESP, 2001.

CONSELHO NACIONAL DA SAÚDE - CNS. A prática do controle social:

conselhos de saúde e financiamento do SUS. Brasília: Ministério da Saúde, 2003.

CORTES, Soraya M. V. Construindo a possibilidade da participação dos usuários: conselhos e conferências no Sistema Único de Saúde. Sociologias, Porto Alegre, v. 7, p. 18-49, 2002.

CORTES, Soraya V. (org.). Participação e saúde no Brasil. Rio de Janeiro: FIOCRUZ, 2009.

FERREIRA, Eliza B.; OLIVEIRA, Dalila A. Crise da escola e políticas educativas. Belo Horizonte: Autêntica, 2009.

FREIRE, Paulo. Pedagogia da esperança: um reencontro com a pedagogia do oprimido. 6. ed. Rio de Janeiro: Paz e Terra, 1999.

KAWASAKI, Clarice S. Universidades públicas e sociedade: uma parceria necessária. Rev. Fac. Educ., São Paulo, v. 23, n. 1-2, p. 239-257, 1997.

MINISTÉRIO DA SAÚDE. Guia do conselheiro: curso de capacitação de conselheiros estaduais e municipais de saúde. Brasília: Ministério da Saúde, 2002.

MITRE, Sandra M. et al. Metodologias ativas de ensino-aprendizagem na formação profissional em saúde: debates atuais. Ciência \& Saúde Coletiva, Rio de Janeiro, v. 13, n. 2, p. 2133-44, 2008.

PINTO, Hêider A.; FRANCO, Túlio B.; MERHY, Emerson E. Fundação estatal e o fortalecimento da capacidade de ação do Estado. Disponível em:

http://www.professores.uff.br/tuliofranco/textos/fundacao-estatalfortalecimento-capacidade-acao.pdf. Acesso em: 17 mar. 2020.

SANTOS, Boaventura de S. Pela mão de Alice: o social e o político na pósmodernidade. 7. ed. São Paulo: Cortez, 1999.

SANTOS, Boaventura de S.; ALMEIDA FILHO, Naomar. A universidade do século XXI: para uma universidade nova. Coimbra. 2008. Disponível em: https://ape.unesp.br/pdi/execucao/artigos/universidade/AUniversidadenoSeculo XXI.pdf. Acesso em: 17 mar. 2020.

SANTOS, Milton. Da totalidade ao lugar. São Paulo: EDUSP, 2005.

SCHMIDT, Maria Luisa Sandoval. Pesquisa participante: alteridade e comunidades interpretativas. Psicol. USP, São Paulo, v. 17, n. 2, p. 11-41, 2006. Disponível em: https://www.scielo.br/scielo.php?pid=S010365642006000200002\&script=sci abstract\&tlng=pt. Acesso em: 10 out. 2019.

SILVA, Alessandra X.; CRUZ, Eliane A.; MELO, Verbena. A importância da informação em saúde para o exercício do controle social. Ciência \& Saúde Coletiva, Rio de Janeiro, v. 12, n. 3, p. 683-688, 2007.

SOBRAL, Fernanda. A. da F. Educação para a competitividade ou para a cidadania social?. São Paulo em Perspectiva, São Paulo, v. 14, n. 1, p. 3-11, 2000. 